\title{
Bardet- Biedl syndrome - A rare case
}

\author{
Madhusmita Behera, ${ }^{1, *}$, Samir Patra ${ }^{2}$ \\ ${ }^{1}$ Consultant, Dept. of Oculoplast and Cataract, Rotary Narayana Nethralaya, Kolkata, ${ }^{2}$ Consultant, Ispat General Hospital, \\ Rourkela, Odisha, India
}

*Corresponding Author: Madhusmita Behera

Email: madhusmita.behera@ rediffmail.com

\begin{abstract}
Bardet-Biedl syndrome (BBS) is a rare autosomal recessive disorder with wide spectrum of clinical features. BBs is distinguished from the much rarer Laurence-moon syndrome, in which retinal pigmentary degeneration, mental retardation, and hypogonadism occur in association with progressive spastic paraparesis and distal muscle weakness, but without polydactyly. Most common feature of BBS is retinal dystrophy. The visual prognosis for children with Bardet-Biedl syndrome is poor.
\end{abstract}

Keywords: Mental retardation, Pigmentary retinopathy, Polydactyly.

\section{Introduction}

Bardet-Biedl syndrome (BBS) is a rare autosomal recessive disorder with wide spectrum of clinical features that produces many effects and affects many body systems. Its main features are obesity, pigmentary retinopathy, polydactyly, hypogonadism and mental retardation and renal dysfunction. ${ }^{1}$ BBS expression varies both within and between families and diagnosis is often difficult. The average age at diagnosis is 9 years. Diagnosis is made by clinical findings. Twelve genes are known to be associated with BBS. ${ }^{2}$

\section{Case Report}

An 11 years old boy presented with chief complaint of decreased vision mainly in the night. There was no history of any consanguineous marriage between parents. The birth of the patient was normal. He had learning disability from birth.

On systemic examination patient was obese with BMI $\left(30.3 \mathrm{~kg} / \mathrm{m}^{2}\right)$, and mental development was lagged behind the normal range. There was presence of polydactyl (hexadactyly) (Fig. 1), hypogonadism but auditory and cardiovascular systems were within normal limits.

On ophthalmic examination patient was orthophoric, ocular movements were full in all directions of gaze in both the eyes.

The best correction visual acuity was counting finger 5 meters in both the eyes. On slit lamp examination of anterior segment of eye was within normal limits. Fundus examination showed bulls eye maculopathy with mid peripheral pigmentary changes with bony spicules, arteriolar constriction with mild pallor of the disc (waxy) (Fig. 2 and Fig. 3).

Laboratory investigation, urine examination, kidney function tests, complete hemogram with ESR were within normal limits. Chest and abdominal X- ray were normal. Abdominal USG and ECG were also within normal limits.

\section{Discussion}

Laurence-moon (Bardet) Biedl syndrome is a rare disorder first defined by Bardet in $1920 .^{3}$ BBS is distinguished from the much rarer Laurence-moon syndrome, in which retinal pigmentary degeneration, mental retardation, and hypogonadism occur in association with progressive spastic paraparesis and distal muscle weakness, but without polydactyly. ${ }^{4}$

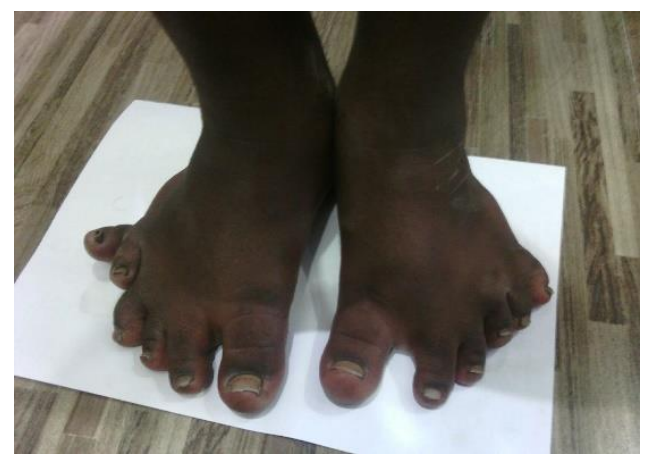

Fig. 1: Polydactyly of both the feet

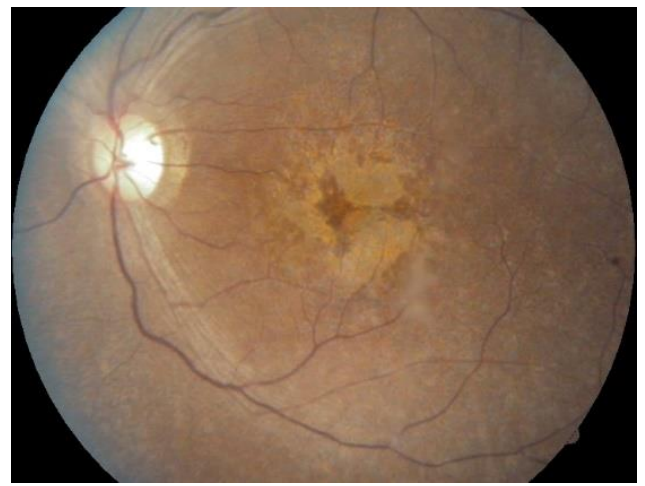

Fig. 2: Fundus of left eye showing bulls eye maculopathy 


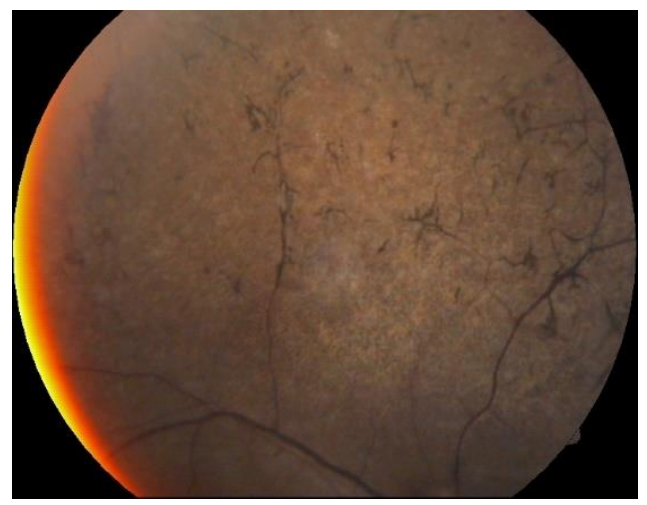

Fig. 3 Fundus showing bony spicules mainly in the mid periphery

Most common feature of BBS is retinal dystrophy. The retinal appearance is variable, with typical retinitis pigmentosa may be present in only few cases. ${ }^{5}$ Other features of BBS are obesity, polydactyly, mental retardation, hypogonadism and renal dysfunction. Other associated features can be hepatic fibrosis, diabetes mellitus, reproductive abnormalities, endocrinological abnormalities, short stature, developmental delay and speech deficit, not always present.

Patients generally has onset of symptoms within the first 10 years life and most often the first complaint is poor night vision. ${ }^{6}$ Nystgmus may be a common feature. The visual prognosis for children with BardetBiedl syndrome is poor, progressive loss of visual acuity arises early in life in the first decade of life.

\section{Conclusion}

The index case has many common features of Laurence Moon Bardet Biedl syndrome including polydactyly, obesity, mental retardation, hypogonadism and retinitis pigmentosa.

\section{Funding/Support: None}

\section{References}

1. Green JS, Parfrey PS, Harnett JD, Farid NR, Cramer BC, Johnson G. et al. The cardinal manifestations of BardetBiedl syndrome, a form of Laurence-Moon-Biedl syndrome. N Engl J Med. 1989;321:1002-1009.

2. Nachury MV, Loktev AV, Zhang Q, Westlake CJ, Peränen J, Merdes A. et al. A core complex of BBS proteins cooperates with GTPase Rab8 to promote ciliary membrane biogenesis. Cell. 2007;129:1201-13.

3. McLoughlin TG, Shanklin DR. Pathology of LaurenceMoon-Bardet-Biedl syndrome. J Pathol Bacteriol. 1967;93:65-79.

4. Laurence JZ, Moon RC. Four cases of "retinitis pigmentosa" occurring in the same family, and accompanied by general imperfections of development. Ophthalmol Rev. 1866; 2:32-4.

5. Ingster-Moati I, Rigaudiere F, Choltus-De Petigny MC, Bremond-Gignac D, Lestrade C, Grall Y. Functional visual explorations of Bardet-Biedl syndrome. A study of three cases. J Fr Ophtalmol. 2000;23:802-8.

6. Riise R, Andreasson S, Wright AF, Tornqvist K. Ocular findings in LM(B)B syndrome. Acta Ophthalmol Scand. 1996;74:612-7.

How to cite this article: Behera $\mathrm{M}$, Patra $\mathrm{S}$. Bardet- Biedl syndrome - A rare case. Indian $\mathrm{J}$ Clin Exp Ophthalmol.2018;4(4):554-555. 